\section{Mechanical Preparation Showed Superior Shaping Ability than Manual Technique in Primary Molars - A Micro-Computed Tomography Study}

Lídia Regina da Costa Hidalgo ${ }^{1}$, Léa Assed Bezerra da Silva' ${ }^{1}$ Graziela Bianchi Leoni ${ }^{2}$, Jardel Francisco Mazzi-Chaves ${ }^{3}$ Emily Eduardo da Silva Carvalho², Alberto Consolaro' ${ }^{1}$, Manoel Damião Sousa-Neto ${ }^{3}$

\author{
'Department of Paediatric Dentistry, \\ Dental School of Ribeirão Preto, \\ USP - Universidade de São Paulo, \\ Ribeirão Preto, SP, Brazil \\ ${ }^{2}$ Department of Endodontics, School \\ of Dentistry, University of Ribeirão \\ Preto, Ribeirão Preto, SP, Brazil \\ ${ }^{3}$ Department of Restorative Dentistry, \\ School of Dentistry of Ribeirão \\ Preto, USP - Universidade de São \\ Paulo, Ribeirão Preto, SP, Brazil
}

Correspondence: Manoel Damião Sousa-Neto, Rua Célia de Oliveira Meirelles 350, 14024-070 Ribeirão Preto, SP, Brasil. Tel: +55-16-36036783. e-mail: sousanet@forp.usp.br

Key Words: primary teeth, root canal preparation, microcomputed tomography, self-adjusting file, rotary system.

\section{Introduction}

In cases of primary molars with irreversibly inflamed or necrotic pulp, the endodontic treatment is considered as a conservative therapy, since it maintains these teeth until their physiological exfoliation. The maintenance of primary teeth contributes to mastication, phonation, and aesthetics, and avoids development of deleterious oral habits. Furthermore, the maintenance of primary teeth prevents changes in chronology and eruption sequence of permanent teeth $(1,2)$.

Manual instrumentation is still reported as the main choice in the primary teeth preparation, but studies have shown limitations to its use, with the possibility of ledge formation, perforations, dentin compaction and instrument fracture (3). On the other hand, rotary instrumentation dramatically reduces the working time, which is a very interesting aspect to consider for pediatric patients (1,3-10).

When planning and deciding on the cleaning and shaping protocol for primary teeth, their morphological characteristics must be considered $(1,11)$, especially for posterior teeth, which have shorter and more curved roots, thinner dentin walls and ectopic surface resorption and a root canal system (RCS) characterized by a ribbon-shaped morphology (12). It is therefore important to choose instruments that maintain the original canal shape without producing deviations and provide a uniform removal of dentin from the canal walls.

A recent study (12), evaluating the primary molar teeth anatomy suggested that Self-Adjusting File (SAF) instrument could be an alternative for cleaning and shaping these teeth, since the proposal of this instrument is its tridimensional adaptation to the root canal walls producing uniform removal around the root canal perimeter, as opposed to only preparing the canal's central portion with a round shape (13-17).

At the same time, ProTaper Next (PTN) emerged as a system designed to combine the most proven performance features from the past with the most recent technological advancements. This system is claimed to simplify rotary shaping procedures by reducing the number of files to 
(3) significant design features, including progressive percentage tapers on a single file, M-wire technology and the offset design (18). To the best authors' knowledge, there are no studies evaluating ProTaper Next system in the preparation of root canals of primary teeth.

Cleaning and shaping of the RCS of primary teeth has been traditionally evaluated by destructive methods that do not provide a three-dimensional analysis of the specimens, such as clearing technique, Indian ink injection $(3,5,7,8)$ and serial sectioning into root slices (4). Moreover, two recent studies $(9,10)$ showed the use of computed tomography (CT) in the assessment of root canal preparation of primary teeth. Is noteworthy that although there are no studies that assess the biomechanical preparation in primary teeth using micro-computed tomography (micro-CT), this methodology has been commonly used for this purpose in permanent teeth, as it allows a three-dimensional noninvasive assessment of the RCS and root canal preparation $(12,14-16)$.

Considering the morphological characteristics of primary teeth, the concept of minimum and uniform removal of dentin from canal walls and the limited knowledge of shaping procedures in primary teeth for a more predictable endodontic treatment, the aim of this study was to evaluate qualitatively and quantitatively the preparation of root canals of primary molars with hand files, ProTaper Next and SAF, using micro-CT scanning.

\section{Material and Methods}

\section{Selection and Preparation of Specimens}

For sample size calculation, SigmaPlot 11.0 statistical software (Systat Software Inc., San Jose, CA, USA) was used based on the following pre-established parameters from a pilot study. For both morphometric data and transportation variables, the minimum detectable difference (MDD) between the means equal to 0.90 and 0.70 and variation coefficient equal to 0.50 and 0.40 , respectively. An alphatype error of 0.05 , power beta of 0.8 and number of groups of 2 were considered. With these results, the estimated minimum sample per group was found to be 7 specimens for morphometric data and 8 for transportation analysis. Therefore, after Ethics Committee approval, 24 primary mandibular molars with physiological root resorption limited to the apical third were selected from a pool of extracted teeth and stored in $0.1 \%$ thymol solution until the moment of use.

After washing in running water, coronal opening was performed on the occlusal surface using round diamond burs (\# 1012; KG Sorensen, Barueri, SP, Brazil) and tapered carbide burs with non-cutting tip (Endo-Z; Dentsply Maillefer), in high rotation, aiming to obtain an trapezoidal shape. After that, the root canals were irrigated with $5 \mathrm{~mL}$ of $1 \% \mathrm{NaOCl}$ and, to facilitate the positioning of the tooth during experimental steps, a self-curing resin custommade mold for each tooth was made. Apical patency was confirmed by inserting a size $10 \mathrm{~K}$-file (Dentsply Maillefer) into the root canal until its tip was visible at the apical foramen and the working length (WL) was set $1.0 \mathrm{~mm}$ shorter of this measure. Size 15 and 20 hand files were used at the WL to create a glide path $(15,16)$. A single experienced operator performed all preparations.

The specimens were scanned using a micro-CT scanner (SkyScan 1174v2; Bruker-micro-CT, Kontich, Belgium) operated at $50 \mathrm{kV}, 800 \mathrm{~mA}$ (0.5-mm Al filter) and isotropic resolution of $16.7 \mu \mathrm{m}$. The scanning was performed by $180^{\circ}$ rotation around the vertical axis with a rotation step of $1^{\circ}$ $(12,15,16)$. Subsequently, these 24 teeth were matched to create eight groups of three based on the morphological aspects of the root canals (volume, surface area and 3D model). Then, one tooth from each group was randomly assigned to one of the 3 experimental groups $(n=8)$ according to the root canal instrumentation technique: hand files (HF), ProTaper Next rotary system (PTN; Dentsply Maillefer) and Self-Adjusting File system (SAF) (ReDent Nova, Ra'anana, Israel) (Fig. 1).

\section{Root Canal Preparation with Hand Files}

The root canals were instrumented manually using crown-down technique with K files (Dentsply Maillefer) up to a \#50 size file. Canals were irrigated with $1 \% \mathrm{NaOCl} 1 \mathrm{~mm}$ shorter at each instrument change, using a total of $20 \mathrm{~mL}$.

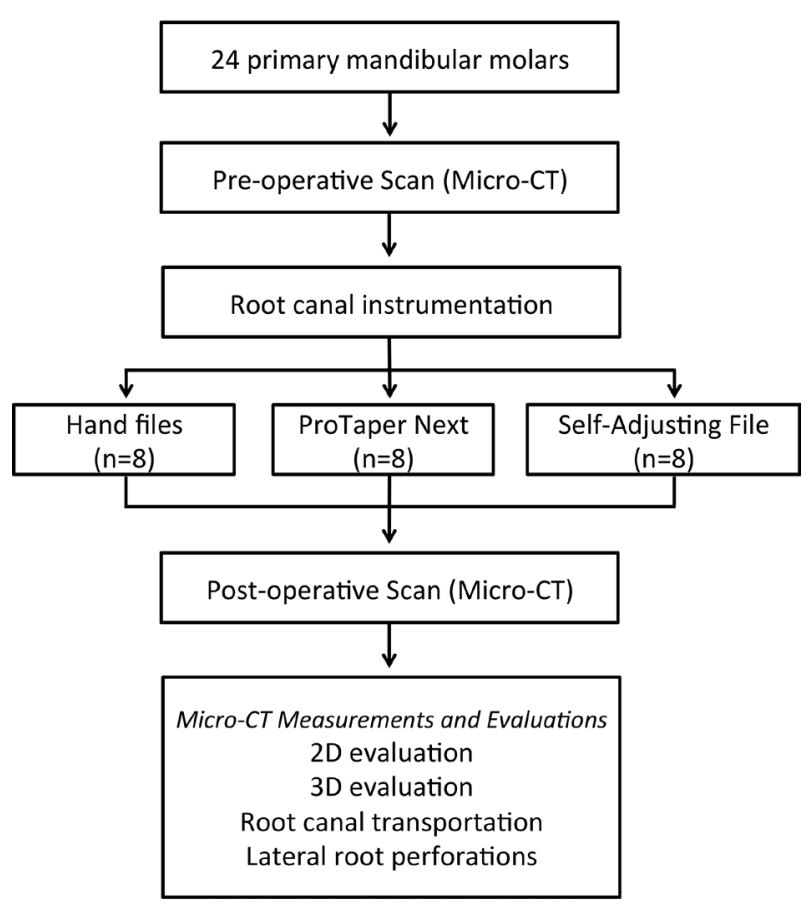

Figure 1. Diagram representation of study design. 


\section{Root Canal Preparation with ProTaper Next System (PTN)}

PTN files were powered by $\mathrm{X}-\mathrm{Smart}{ }^{\mathrm{TM}}$ endodontic micromotor (Dentsply/Maillefer) at a rotational speed of $300 \mathrm{rpm}$ and $200 \mathrm{~g} / \mathrm{cm}$ torque with in-and-out pecking motion combined with brushing action. Initially was used the Protaper Universal SX and next were used Protaper Next $X 1, X 2$ and $X 3$ files. Canals were irrigated with $1 \%$ $\mathrm{NaOCl} 1 \mathrm{~mm}$ shorter at each instrument change, using a total of $20 \mathrm{~mL}$.

\section{Root Canal Preparation with SAF}

A $1.5-\mathrm{mm}$ diameter SAF instrument was operated to the WL with an in-and-out motion using a vibrating handpiece (GentlePower Lux 20LP; KaVo, Biberach, Germany) combined with a RDT3 head (ReDent-Nova) at a frequency of $83.3 \mathrm{~Hz}$ (5000 rpm) and amplitude of $0.4 \mathrm{~mm}$ for a total time of $4 \mathrm{~min}$ per canal. During the procedure, a continuous irrigation with $1.0 \% \mathrm{NaOCl}$ with flow rate of $5 \mathrm{~mL} / \mathrm{min}$ was applied by a special irrigation apparatus (VATEA, ReDent-Nova).

\section{Micro-CT Measurements and Evaluations}

The teeth were scanned again after canal preparation using the same parameters described for the preoperative analysis. The pre- and postoperative images were reconstructed using NRecon v.1.6.6.0 software (Brukermicro-CT) and superimposed using a co-registration tool of DataViewer v.1.5.0 software (Bruker-micro-CT). CTAn v.1.14.4.1+ software (Bruker-micro-CT) was used for the $2 \mathrm{D}$ evaluation of the root canals at $1 \mathrm{~mm}$ from the apical foramen (area, perimeter, roundness, major diameter and minor diameter) and 3D evaluation of the canals from the cement enamel junction to the apex (volume, surface area and structure model index). The structure model index (SMI) involves a measurement of surface convexity in a 3D structure. An ideal plate, cylinder and sphere have SMI values of 0,3 , and 4 , respectively $(12,15,16)$. The mean increase $(\Delta)$ of each $2 D$ and $3 D$ parameter was calculated by subtracting the postoperative values from the preoperative values. Color-coded root canal models (green indicating preoperative and red indicating postoperative canal surfaces) enabled qualitative comparison of the matched root canals before and after shaping using CTVol v.2.2.3.0 software (Bruker-micro-CT) $(15,16)$.

Root canal transportation (in $\mathrm{mm}$ ) was calculated by the mean difference between the centers of gravity for each apical slice before and after canal preparation. The size of the lateral root perforations (in $\mathrm{mm}$ ) after preparation of each canal was also evaluated using CTAn v.1.14.4.1+ software (Bruker-micro-CT), according to the following classification: (a) absent, (b) than $1 \mathrm{~mm}$, (c) between 1 and $2 \mathrm{~mm}$ and (d) larger than $2 \mathrm{~mm}$. A single experienced operator performed all micro-CT analyses.

\section{Statistical Analysis}

After normality assumptions (Shapiro-Wilk test) and homogeneity of the variance (Levene test) were verified, the pre- and postoperative results for the $2 \mathrm{D}$ and $3 \mathrm{D}$ parameters were compared using paired-t test. The mean increase $(\Delta)$ of each parameter was compared among the groups by one-way ANOVA and post hoc Tukey's test, and the lateral perforations scores were compared using Kruskal-Wallis and Dunn's tests. SPSS v17.0 for Windows software (SPSS Inc., Chicago, IL, USA) was employed for all analyses with the level of statistical significance set at 5\%. Kappa test was utilized to determinate the intra-examiner agreement (Kappa $\geq 0.85$ ).

\section{Results}

The results of the 2D and 3D quantitative analysis are presented in Table 1. The preoperative analysis showed no statistically significant difference among the canals ( $p>0.05)$. The paired-t test showed that all the canal preparation techniques increased significantly the area, minor diameter, volume and surface area of the mesial and distal canals. SAF group presented the smallest mean increase of area, minor diameter, volume and surface area of the mesial and distal canal compared with $\mathrm{HF}$ and PTN groups $(p<0.05)$. No significant difference was found among the groups regarding the major diameter ( $p>0.05)$. The shape (roundness) of both mesial and distal canals had greater alteration in the PTN group $(p<0.05)$.

In the pre-preparation qualitative analysis (green), the 3D models showed the complexity of the RCS in primary molars with isthmuses and flattened areas (Fig. $2 \mathrm{~A})$. The changes in canal shape, shown by overlapping of unprepared canals (green) and prepared areas (red), showed an increase in canal contouring in all groups, being possible to observe greater transportation in HF group compared with the PTN and SAF groups, which exhibited more centered preparations, particularly in curved areas (Fig. 2B). A more uniform removal of dentin mass along the canal perimeter was observed in the SAF group. HF and PTN groups showed a more accentuated dentin removal from the inner canal walls towards the furcation region (danger area) (Figs. 2C and 2D).

SAF group showed lower apical transportation than HF group $(p<0.05)$ and PTN group had intermediate values (Table 2). Lateral perforations were less frequent $(p<0.05)$ in SAF (4.2\%) and PTN (7.7\%) groups compared with HF group (47.8\%) (Fig. 3). SAF and PTN groups presented lateral perforations smaller than $1 \mathrm{~mm}$ while the $\mathrm{HF}$ groups presented lateral perforations larger than $2 \mathrm{~mm}$ 
(Fig. 3). Figure 4 exhibits irregularities and thinner dentin walls due to physiological root resorption before canal preparation, and the location and extent of perforations after biomechanical preparation.

\section{Discussion}

It is important to evaluate the action of different instruments on root canal geometry in different roots and tooth groups for endodontic treatment in primary teeth. Therefore, the objective of this study was to evaluate root canal preparation in primary mandibular molars with hand, ProTaper Next and SAF files, using micro-CT analysis.

Micro-CT analysis is a high-cost, labor-intensive and time-consuming methodology, which presents a steep learning curve to get the required expertise to extract quantitative data (19). Then, to ensure the internal validity of the experiment, the experienced and calibrated operator performed all micro-CT analyses.

Micro-CT scanning is a non-invasive and nondestructive technique that allows an accurate assessment of morphological characteristics of the RCS and the impact of the alterations occurred during the different phases of the endodontic treatment. While it is currently the methodology used in ex vivo studies of canal preparation in permanent teeth $(14-16,20,21)$, the review of literature shows few studies using micro-CT to evaluate changes in

Table 1. Morphometric data (media \pm standard deviation) of the mesial and distal roots canals of primary mandibular molars before and after instrumentation with hand, ProTaper Next and SAF files at $1 \mathrm{~mm}$ from the apical foramen.

\begin{tabular}{|c|c|c|c|c|c|c|}
\hline & \multicolumn{3}{|c|}{ Mesial root } & \multicolumn{3}{|c|}{ Distal root } \\
\hline & \multicolumn{3}{|c|}{ Experimental Groups } & \multicolumn{3}{|c|}{ Experimental Groups } \\
\hline & Manual & PTN & SAF & Manual & PTN & SAF \\
\hline Length (mm) & $7.79 \pm 1.25$ & $7.80 \pm 1.39$ & $7.89 \pm 0.63$ & $7.08 \pm 2.74$ & $6.14 \pm 1.67$ & $7.78 \pm 2.02$ \\
\hline Area (mm2) (initial) & $0.26 \pm 0.40$ & $0.15 \pm 0.14$ & $0.23 \pm 0.32$ & $0.38 \pm 0.33$ & $0.37 \pm 0.34$ & $0.27 \pm 0.29$ \\
\hline After preparation & $0.34 \pm 0.42$ & $0.22 \pm 0.13$ & $0.25 \pm 0.32$ & $0.51 \pm 0.34$ & $0.52 \pm 0.39$ & $0.30 \pm 0.30$ \\
\hline$\Delta$ & $0.07 \pm 0.05 \mathrm{~A}$ & $0.07 \pm 0.04 \mathrm{~A}$ & $0.02 \pm 0.01 \mathrm{~B}$ & $0.13 \pm 0.10 \mathrm{~A}$ & $0.14 \pm 0.09 \mathrm{~A}$ & $0.03 \pm 0.03 B$ \\
\hline Perimeter (mm) (initial) & $2.08 \pm 1.71$ & $1.55 \pm 0.81$ & $2.29 \pm 1.97$ & $3.21 \pm 2.41$ & $3.38 \pm 2.74$ & $2.48 \pm 1.68$ \\
\hline After preparation & $2.42 \pm 1.74$ & $1.89 \pm 0.63$ & $2.37 \pm 1.97$ & $3.70 \pm 2.28$ & $3.77 \pm 2.68$ & $2.63 \pm 1.56$ \\
\hline$\Delta$ & $0.35 \pm 0.24 \mathrm{~A}$ & $0.34 \pm 0.32 \mathrm{~A}$ & $0.07 \pm 0.04 \mathrm{~B}$ & $0.35 \pm 0.22 \mathrm{~A}$ & $0.29 \pm 0.13 \mathrm{AB}$ & $0.10 \pm 0.08 \mathrm{~B}$ \\
\hline Roundness (initial) & $0.46 \pm 0.16$ & $0.48 \pm 0.17$ & $0.42 \pm 0.24$ & $0.36 \pm 0.17$ & $0.30 \pm 0.19$ & $0.32 \pm 0.17$ \\
\hline After preparation & $0.56 \pm 0.18$ & $0.62 \pm 0.22$ & $0.48 \pm 0.26$ & $0.42 \pm 0.18$ & $0.46 \pm 0.28$ & $0.38 \pm 0.20$ \\
\hline$\Delta$ & $0.10 \pm 0.09 \mathrm{AB}$ & $0.16 \pm 0.13 \mathrm{~A}$ & $0.05 \pm 0.05 \mathrm{~B}$ & $0.03 \pm 0.03 \mathrm{~B}$ & $0.19 \pm 0.23 \mathrm{~A}$ & $0.03 \pm 0.04 \mathrm{~B}$ \\
\hline Major diameter (mm) (initial) & $0.82 \pm 0.71$ & $0.62 \pm 0.34$ & $0.94 \pm 0.86$ & $1.28 \pm 1.04$ & $1.43 \pm 1.18$ & $1.04 \pm 0.73$ \\
\hline After preparation & $0.92 \pm 0.70$ & $0.70 \pm 0.30$ & $0.98 \pm 0.87$ & $1.41 \pm 0.98$ & $1.54 \pm 1.22$ & $1.10 \pm 0.71$ \\
\hline$\Delta$ & $0.07 \pm 0.06 \mathrm{~A}$ & $0.06 \pm 0.06 \mathrm{~A}$ & $0.04 \pm 0.02 \mathrm{~A}$ & $0.06 \pm 0.07 \mathrm{~A}$ & $0.02 \pm 0.04 \mathrm{~A}$ & $0.04 \pm 0.02 \mathrm{~A}$ \\
\hline Minor diameter (mm) (initial) & $0.37 \pm 0.21$ & $0.30 \pm 0.13$ & $0.31 \pm 0.18$ & $0.39 \pm 0.21$ & $0.31 \pm 0.17$ & $0.31 \pm 0.17$ \\
\hline After preparation & $0.48 \pm 0.21$ & $0.46 \pm 0.10$ & $036 \pm 0.17$ & $0.58 \pm 0.17$ & $0.52 \pm 0.07$ & $0.39 \pm 0.16$ \\
\hline$\Delta$ & $0.11 \pm 0.07 \mathrm{~A}$ & $0.16 \pm 0.07 \mathrm{~A}$ & $0.05 \pm 0.04 \mathrm{~B}$ & $0.19 \pm 0.12 \mathrm{~A}$ & $0.21 \pm 0.13 \mathrm{~A}$ & $0.07 \pm 0.07 \mathrm{~B}$ \\
\hline Volume (mm3) (initial) & $6.35 \pm 3.81$ & $5.88 \pm 3.61$ & $6.81 \pm 4.10$ & $7.90 \pm 4.09$ & $7.79 \pm 5.57$ & $7.56 \pm 5.22$ \\
\hline After preparation & $7.97 \pm 3.95$ & $7.57 \pm 3.72$ & $7.30 \pm 4.07$ & $9.57 \pm 4.46$ & $9.41 \pm 6.19$ & $7.98 \pm 5.57$ \\
\hline$\Delta$ & $1.62 \pm 0.90 \mathrm{~A}$ & $1.69 \pm 0.52 \mathrm{~A}$ & $0.50 \pm 0.29 \mathrm{~B}$ & $1.67 \pm 1.10 \mathrm{~A}$ & $1.62 \pm 0.78 \mathrm{~A}$ & $0.42 \pm 0.55 \mathrm{~B}$ \\
\hline Surface Area (mm2) (initial) & $52.83 \pm 16.85$ & $46.99 \pm 20.34$ & $55.93 \pm 21.15$ & $52.80 \pm 19.01$ & $50.85 \pm 26.18$ & $49.67 \pm 24.84$ \\
\hline After preparation & $57.01 \pm 16.22$ & $50.74 \pm 19.70$ & $57.38 \pm 20.51$ & $56.41 \pm 19.27$ & $52.80 \pm 26.82$ & $50.70 \pm 24.69$ \\
\hline$\Delta$ & $4.19 \pm 2.92 \mathrm{~A}$ & $3.75 \pm 2.59 \mathrm{~A}$ & $1.45 \pm 1.59 \mathrm{~B}$ & $2.31 \pm 1.45 \mathrm{~A}$ & $2.23 \pm 1.61 \mathrm{~A}$ & $0.39 \pm 0.41 \mathrm{~B}$ \\
\hline SMI (initial) & $1.82 \pm 0.44$ & $2.12 \pm 0.45$ & $1.70 \pm 0.50$ & $1.76 \pm 0.53$ & $1.60 \pm 0.35$ & $1.97 \pm 0.25$ \\
\hline After preparation & $2.12 \pm 0.35$ & $2.25 \pm 0.43$ & $1.85 \pm 0.57$ & $1.90 \pm 0.55$ & $1.90 \pm 0.37$ & $2.07 \pm 0.26$ \\
\hline$\Delta$ & $0.25 \pm 0.16 \mathrm{~A}$ & $0.16 \pm 0.07 \mathrm{AB}$ & $0.05 \pm 0.03 \mathrm{~B}$ & $0.16 \pm 0.08 \mathrm{~A}$ & $0.18 \pm 0.18 \mathrm{~A}$ & $0.10 \pm 0.05 \mathrm{~A}$ \\
\hline
\end{tabular}

$\Delta$, mean increase $( \pm$ standard deviation) of the analysed parameter. Different superscript letters in the same line indicate statistical significant difference between groups (Tukey test, $\mathrm{P}<.05$ ). Within groups, values with bold letters in the same column were not statistically different (paired $t$ test, $\mathrm{P}>.05)$. 
the root canals of primary teeth after instrumentation.

Variations in canal geometry before shaping procedures seem to have more influence on the changes observed after preparation than the instrumentation techniques per se $(16,22)$. Therefore, in the present study, attempts were made to create a reliable baseline, thus ensuring the comparison
A

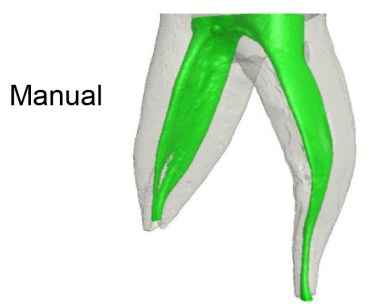

PTN
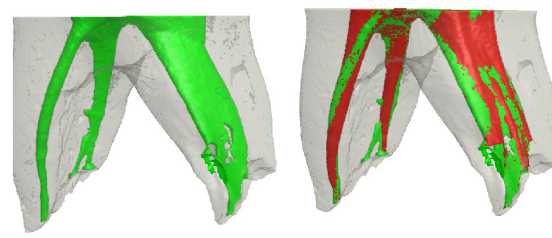

SAF

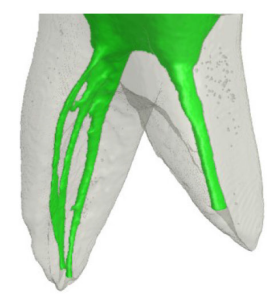

B

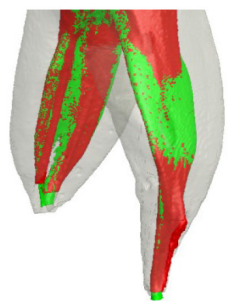

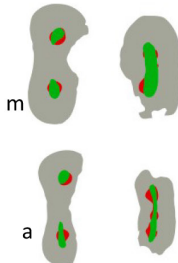

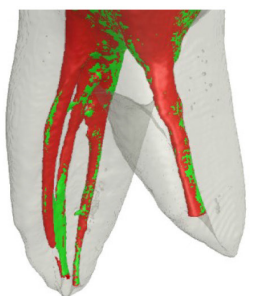

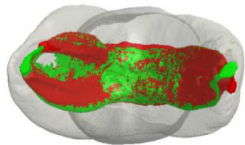
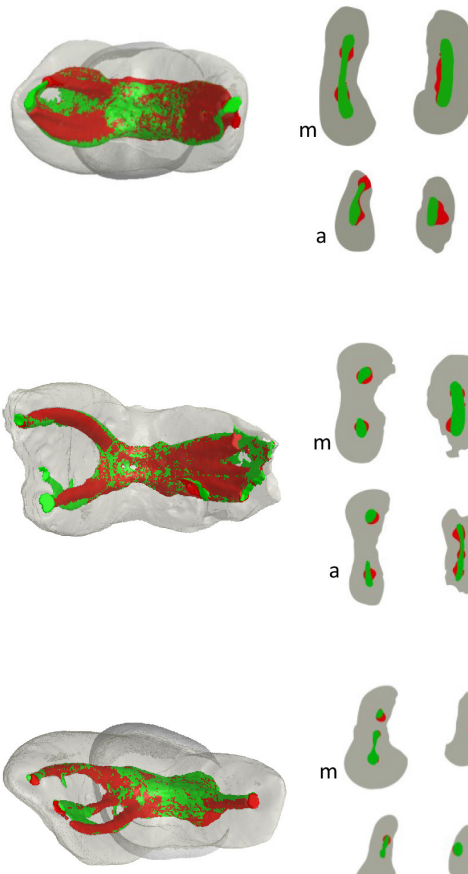
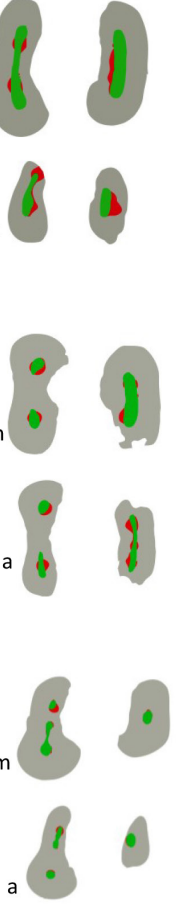

Figure 2. Representative 2D and 3D reconstructions of the internal and external anatomy of the primary mandibular first molars before and after root canal preparation with hand, ProTaper Next and SAF files. (A) Preoperative 3D models of the internal root canal anatomy. (B) Buccal view of superimposed 3D models before (green) and after (red) root canal preparation. (C) Apical view of superimposed 3D models before (green) and after (red) root canal preparation. (D) Representative cross-sections of the superimposed root canals before (green) and after (red) preparation at the middle $(\mathrm{m})$ and apical (a) thirds.

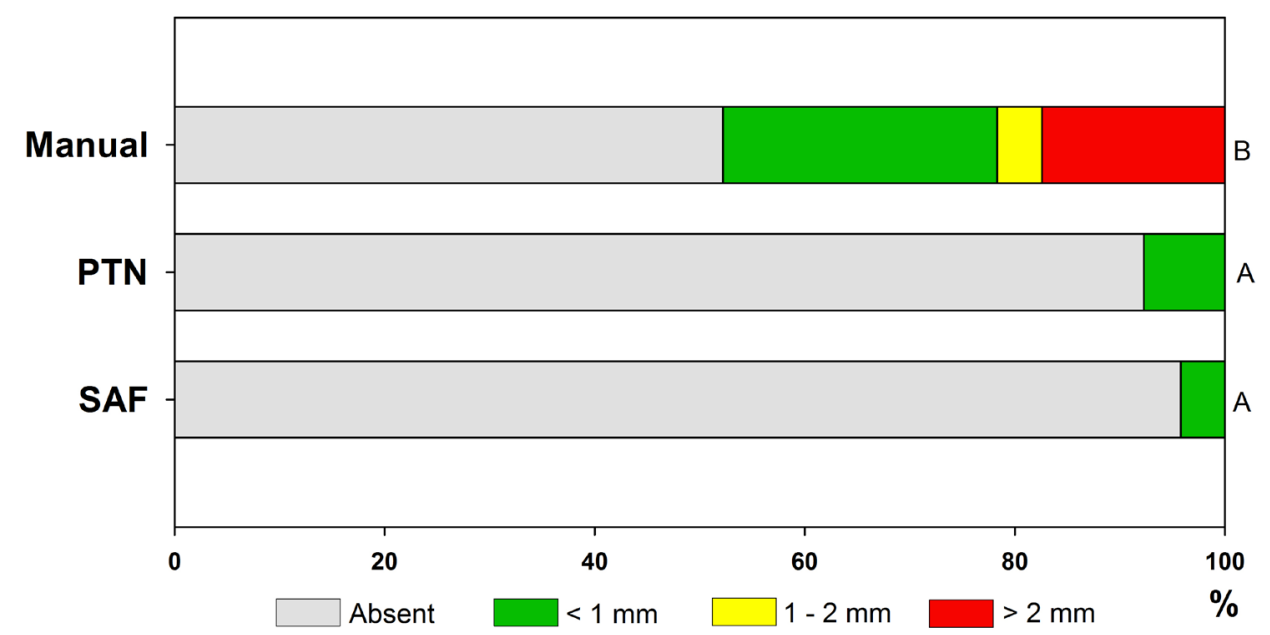

Figure 3. Distribution (\%) of lateral perforations after root canal preparation with hand, ProTaper Next and SAF files. Different letters mean statistically significant difference $(\mathrm{p}<0.05)$. 
of groups for preoperative morphologic parameters.

SAF had the lowest mean increase in area, the minor diameter, volume and surface area in both mesial and distal canals. These findings corroborate previous studies in permanent teeth that showed lower dentin removal values with SAF compared with rotary instruments (14-18) and that instruments with different geometrical features produce preparations with different dimensions (23-25). SAF is a hollow, compressible instrument, with a thin abrasive layer on its surface, which expands inside the root canal and circumferentially removes a thin layer of dentin with a back-and-forth grinding motion (17). This results in a preparation with a cross-section similar to the original canal, but only slightly larger $(17,26)$. On the other hand, the metallic structure and cutting efficiency of hand files and Protaper Next may explain their higher dentin removal capacity compared with SAF.

The mean increase in major diameter did not differ among groups possibly due to the shape of the root canals in primary molars (12) as the flattened regions usually remain untouched by the instruments (27).

The cross-sectional shape of the root canal in the apical third was evaluated using the morphometric parameter of roundness $(15,16)$. Roundness was more affected by ProTaper Next, which may be related to the fact that these instruments present increasing percentage taper in the apical portion.

Although PTN presented greater mean increases in the quantitative parameters of the root canal geometry compared with $S A F$, and greater removal of dentin from the canal walls, as seen in the 3D models, canal preparation with PTN also resulted in fewer occurrences of lateral perforations and intermediate behavior in apical transportation. These are important concerns during preparation of primary teeth because of the thinner dentin walls, especially in the danger zone, due to the permanent tooth germ. The manufacturer recommends the use of SAF for 4 min (17) and Protaper Next presents a reduced number of instruments compared with its predecessor, Universal Protaper (18). The chairside team is also relevant in pediatric dentistry as it allows faster procedures while maintaining the
Figure 4. Apical view of 3D models and representative cross-sections of groups HF, PTN and SAF showing irregularities and thinner dentin walls due to physiological root resorption before canal preparation, and the location and extent of perforations observed after canal preparation (black arrows).

Table 2. Transportation (in $\mathrm{mm}$ ) of the mesial and distal roots canals of primary mandibular molars after instrumentation with hand, ProTaper Next and SAF files.

\begin{tabular}{|c|c|c|c|c|c|c|}
\hline & \multicolumn{2}{|c|}{ Manual } & \multicolumn{2}{|c|}{ PTN } & \multicolumn{2}{|c|}{ SAF } \\
\hline & $\operatorname{Mean}_{ \pm} \mathrm{SD}$ & Range & $\operatorname{Mean}_{ \pm} \mathrm{SD}$ & Range & $\operatorname{Mean}_{ \pm} \mathrm{SD}$ & Range \\
\hline Mesial root & $0.14 \pm 0.11 \mathrm{~B}$ & $0.04-0.33$ & $0.09 \pm 0,04 \mathrm{AB}$ & $0,04-0,15$ & $0,05 \pm 0.02 \mathrm{~A}$ & $0.02-0.09$ \\
\hline Distal root & $0.29 \pm 0.17 \mathrm{~B}$ & $0.04 \pm 0.55$ & $0.20 \pm 0.24 \mathrm{AB}$ & $0.03-0,65$ & $0.07 \pm 0.04 \mathrm{~A}$ & $0.03-0.15$ \\
\hline
\end{tabular}

Different superscript letters in the same row indicate statistically significant difference among groups (Tukey's test, $\mathrm{p}<0.05$ ). 
quality and safety, in addition to reducing fatigue for the patient and the professional (4).

In addition to these factors, the 3D models also showed larger deviations in the manual instrumentation group compared with PTN and SAF groups, which exhibited more centered preparations, especially in areas of curvature. Recent studies assessing canal preparation with ProTaper Next instruments in permanent teeth showed lower transportation by these instruments compared with other rotary $\mathrm{Ni}$-Ti systems (20). These files are made of a special NiTi alloy called M-Wire and incorporate a variable taper design and a unique offset mass of rotation, which improves the strength and flexibility along its active part $(18,28)$. This may have contributed to the shaping ability of this instrument especially in the curved areas, since the primary molars have curvatures in both mesial and distal roots (12). Previous studies report that endodontic instruments manufactured with M-alloy wire are more flexible than those manufactured with conventional $\mathrm{Ni}$-Ti alloy $(29,30)$, which in turn are more flexible than the stainless steel hand instruments, which have reduced flexibility (31). In the present study, the manual instrumentation did not maintain the original canal anatomy and caused a greater incidence of lateral perforations and apical transportation. Such results in numerous studies in permanent teeth contraindicate these instruments for preparation of teeth with accentuated root curvature $(24,31)$.

In primary teeth, mechanical instrumentation showed better results than manual instrumentation, producing more centered preparations and a smaller number of lateral perforations and canal transportation. Comparing to the mechanical systems, SAF produced a more homogeneous preparation of primary root canals.

\section{Resumo}

Este estudo avaliou o preparo do canal radicular em molares decíduos com sistema manual e mecanizado [ProTaper Next e Self-Adjusting File (SAF)], por meio de parâmetros morfológicos bi (2D) e tridimensionais (3D) em microtomografia computadorizada (micro-CT). Canais radiculares de 24 molares decíduos foram preparados com limas manuais (M), ProTaper Next (PTN) e SAF ( $n=8 /$ grupo). Os dentes foram escaneados antes e após o preparo do canal radicular e as imagens de micro-CT pré e pós-operatória foram reconstruidas. As mudanças nos parâmetros morfológicos 2D (área, perimetro, circularidade, menor e maior diâmetro) e 3D [volume, área de superficie, indice de estrutura do modelo (SMI)], bem como o transporte do canal radicular e a presença de perfurações laterais foram avaliadas (Kruskal-Wallis and ANOVA; $\alpha=0.05$ ). SAF apresentou menores mudanças no diâmetro menor, volume e área de superfície quando comparado com M e PTN ( $p<0.05)$. PTN mostrou canais mais circulares após o preparo. A análise 3D revelou maior transporte para o grupo M. PTN e SAF mostraram maior centralização do preparo do canal radicular, especialmente em áreas de curvatura. SAF e $M$ apresentaram, respectivamente, o menor $(0,05 \pm 0,02$ e $0,07 \pm 0,04)$ e o maior $(0,14 \pm 0,11$ e $0,29 \pm 0,17)$ transporte apical. Foi possivel observar menor porcentagem de perfurações laterais para os grupos SAF $(4,2 \%)$ e PTN $(7,7 \%)$ comparados ao grupo M $(47,8 \%)$ $(p<0.05)$. Conclui-se que o preparo mecanizado dos canais radiculares em molares decíduos, apresentou melhor capacidade de modelagem do que as limas manuais, promovendo preparos mais centralizados e menor ocorrência de perfurações laterais e transporte do canal.

\section{References}

1. Pinheiro SL, Araujo G, Bincelli I, Cunha R, Bueno C. Evaluation of cleaning capacity and instrumentation time of manual, hybrid and rotary instrumentation techniques in primary molars. Int Endod J 2012;45:379-385.

2. Cleghorn BMB, Boorberg NB, Christie WH. Primary human teeth and their root canal systems. Endod Topics 2012;23: 6-33.

3. Silva LA, Leonardo MR, Nelson-Filho P, Tanomaru JM. Comparison of rotary and manual instrumentation techniques on cleaning capacity and instrumentation time in deciduous molars. J Dent Child (Chic) 2004;71:45-47.

4. Kummer TR, Calvo MC, Cordeiro MM, de Sousa Vieira R, de Carvalho Rocha MJ. Ex vivo study of manual and rotary instrumentation techniques in human primary teeth. Oral Surg Oral Med Oral Pathol Oral Radiol Endod 2008;105: e84-92.

5. Nazari Moghaddam K, Mehran M, Farajian Zadeh H. Root canal cleaning efficacy of rotary and hand files instrumentation in primary molars. Iran Endod J2009;4:53-57.

6. Azar MR, Safi L, Nikaein A. Comparison of the cleaning capacity of Mtwo and Pro Taper rotary systems and manual instruments in primary teeth. Dent Res J (Isfahan) 2012;9:146-151.

7. Seraj B, Ramezani G, Ghadimi S, Mosharrafian SH, Motahhary P, Safari M. In-vitro comparison of instrumentation time and cleaning capacity between endodontic hand piece and manual preparation techniques in primary molar teeth. Minerva Stomatol 2013;62:17-22.

8. Katge F, Patil D, Poojari M, Pimpale J, Shitoot A, Rusawat B. Comparison of instrumentation time and cleaning efficacy of manual instrumentation, rotary systems and reciprocating systems in primary teeth: an in vitro study. J Indian Soc Pedod Prev Dent 2014;32:311-316.

9. Selvakumar $H_{1}$ Anandhan V, Thomas E, Swaminathan K, Vijayakumar R. Evaluation of canal transportation and centering ability of $\mathrm{K} 3$ $(0.02 \%)$ and $\mathrm{K} 3(0.04 \%)$ with hand $\mathrm{K}$ files in primary teeth using spiral computed tomography. J Indian Soc Pedod Prev Dent 2014;32:286-291.

10. Poornima PDP, Nagaveni NB, Roopa KB, Bharath K, Neena IE. Volumetric analysis of hand and rotary root canal instrumentation and filling in primary teeth using Spiral Computed Tomography - an in vitro study. Int J Paediatr Dent 2016;26:193-198.

11. Ahmed HM. Anatomical challenges, electronic working length determination and current developments in root canal preparation of primary molar teeth. Int Endod J 2013;46:1011-1022.

12. Fumes AC, Sousa-Neto MD, Leoni GB, Versiani MA, da Silva LA, da Silva RA, et al.. Root canal morphology of primary molars: a micro-computed tomography study. Eur Arch Paediatr Dent 2014;15:317-326.

13. Siqueira JF, Jr., Alves FR, Almeida BM, de Oliveira JC, Rocas IN. Ability of chemomechanical preparation with either rotary instruments or selfadjusting file to disinfect oval-shaped root canals. J Endod2010;36: 1860-1865.

14. Paque F, Peters OA. Micro-computed tomography evaluation of the preparation of long oval root canals in mandibular molars with the self-adjusting file. J Endod 2011;37: 517-521.

15. Versiani MA, Pecora JD, de Sousa-Neto MD. Flat-oval root canal preparation with self-adjusting file instrument: a micro-computed tomography study. J Endod 2011;37: 1002-1007.

16. Versiani MA, Leoni GB, Steier L, De-Deus G, Tassani S, Pécora JD, et al.. Micro-computed tomography study of oval-shaped canals prepared with the self-adjusting file, Reciproc, WaveOne and ProTaper Universal systems. J Endod 2013;39:1060-1066.

17. Metzger Z, Teperovich E, Zary R, Cohen R, Hof R. The self-adjusting file (SAF). Part 1: respecting the root canal anatomy--a new concept of endodontic files and its implementation. J Endod 2010;36:679-690.

18. Ruddle CJ, Machtou P, West JD. The shaping movement: fifthgeneration technology. Dent Today 2013;32:6-9.

19. De-Deus G, Marins J, Neves A de A, Reis C, Fidel S, Versiani MA, et al.. Assessing accumulated hard-tissue debris using micro-computed 
tomography and free software for image processing and analysis. J Endod 2014;40:271-276.

20. Metzger Z, Zary R, Cohen R, Teperovich E, Paque F. The quality of root canal preparation and root canal obturation in canals treated with rotary versus self-adjusting files: a three-dimensional micro-computed tomographic study. J Endod 2010;36:1569-1573.

21. Zhao D, Shen $Y$, Peng B, Haapasalo M. Root canal preparation of mandibular molars with 3 nickel-titanium rotary instruments: a microcomputed tomographic study. J Endod 2014;40:1860-1864.

22. De-Deus G. Research that matters - root canal filling and leakage studies. Int Endod J 2012;45:1063-1064.

23. Ruddle CJ. Nickel-titanium rotary instruments: current concepts for preparing the root canal system. Aust Endod J 2003;29:87-98.

24. Peters $0 \mathrm{~A}($ ). Current challenges and concepts in the preparation of root canal systems: a review. J Endod 2004;30:559-567.

25. Peters $0 A$, Paque F. Current developments in rotary root canal instrument technology and clinical use: a review. Quintessence Int 2010;41:479-488.

26. Metzger Z, Teperovich E, Cohen R, Zary R, Paque F, Hulsmann M. The self-adjusting file (SAF). Part 3: removal of debris and smear layer-A scanning electron microscope study. J Endod 2010;36:697-702.

27. Kele区 A, Alcin H, Kamalak A, Versiani MA. Oval-shaped canal retreatment with self-adjusting file: a micro-computed tomography study. Clin Oral Investig 12014;8:1147-1153.

28. Pereira ES, Peixoto IF, Viana AC, Oliveira II, Gonzalez BM, Buono VT, et al.. Physical and mechanical properties of a thermomechanically treated NiTi wire used in the manufacture of rotary endodontic instruments. Int Endod J 2012;45:469-674.

29. Ye J, Gao Y. Metallurgical characterization of M-Wire nickel-titanium shape memory alloy used for endodontic rotary instruments during low-cycle fatigue. J Endod 2012;38:105-107.

30. Schafer E. Root canal instruments for manual use: a review. Endod Dent Traumatol 1997;13:51-64.

31. Schafer E, Schulz-Bongert U, Tulus G. Comparison of hand stainless steel and nickel titanium rotary instrumentation: a clinical study. J Endod 2004;30:432-435. 